\title{
La geografía cultural de Luis A. Martínez: espacios e identidad
}

The Cultural Geography of Luis A. Martínez: Spaces and Identity

\section{Emmanuelle Sinardet}

Université Paris Nanterre, Centre d'études équatoriennes, CRIIA-Études romanes EA 369

París, Francia

Artículo de investigación

https://doi.org/10.32719/13900102.2021.49.2

Fecha de recepción: 5 de mayo de 2020

Fecha de aceptación: 12 de junio de 2020 


\section{RESUMEN}

Con la novela A la Costa (1904) de Luis A. Martínez, el espacio de la Costa entra en la narrativa del Ecuador. La relación entre geografía y literatura da fe, aquí, de una original apropiación cultural de la naturaleza costeña, la cual es transformada por las numerosas y detalladas descripciones del narrador en espacios-valores. La autora estudia las modalidades del trato de los espacios y de los paisajes, entre realismo, costumbrismo y romanticismo herderiano, para entender los valores que asumen los espacios costeños; valores que no solo son económicos, políticos o ideológicos, sino también identitarios y hasta espirituales. Se observa cómo van moldeando un genio que remite a un Volkgeist singular en el panorama cultural de la época, por tener una dimensión sublime, la misma que caracteriza, por cierto, la producción pictórica del Martínez paisajista.

Palabras clave: Ecuador, novela, Costa, paisaje, Luis A. Martínez, costumbrismo, identidad, romanticismo.

\section{ABSTRACT}

With the novel A la Costa (1904) by Luis A. Martínez, the Coastal space enters the Ecuadorian narrative. The relationship between geography and literature attests, here, to a unique cultural appropriation of coastal nature, which is transformed by the narrator's numerous and detailed descriptions into space-values. The author studies the modalities by which spaces and landscapes are treated, between realism, costumbrismo and herderian romanticism, in order to understand the values assumed by coastal spaces; values that are not only economic, political or ideological, but also identitary and even spiritual. We observe how they gradually shape a genius that refers to a particular Volkgeist for the cultural panorama of the time, for having a sublime dimension, which also, incidentally characterizes the pictorial production of Martínez as a landscape painter.

KEYwords: Ecuador, novel, Costa, landscape, Luis A. Martínez, costumbrismo, identity, romanticism.

Con la novela $A$ la Costa de Luis Alfredo Martínez, publicada en 1904, la Costa entra en la narrativa nacional, después de la Sierra ( $L a$ emancipada, por ejemplo) e incluso después del Oriente (Cumandá). Aunque un tanto tardía, esta entrada en literatura llama la atención por el trato original de la geografía. El narrador, a manera de topógrafo, va apeando el espacio: lo delimita, lo circunscribe y se apropia de él, nombrándolo a través de un inventario impresionante de elementos y componentes. Por lo que invaden el espacio textual las descripciones de paisajes.

El narrador también subraya la articulación de estos paisajes con las actividades humanas. No olvidemos que el título completo de la novela precisa Costumbres ecuatorianas. La crítica ha subrayado, con razón, las características realistas de la narración, las cuales son patentes en las 
descripciones geográficas, topográficas y botánicas. Pero este realismo no impide una inspiración costumbrista que dibuja a tipos humanos emblemáticos del medio descrito, con sus formas de pensar, de actuar y de hablar incluso. Ahora bien, estos tipos, aunque esquemáticos, no solo personifican idiosincrasias costeñas, sino también psicologías serranas, mediante la construcción de la narración en dos partes simétricas casi: la primera parte se sitúa en la Sierra y en particular en Quito, la segunda, en la Costa. A esta construcción también remite el título de la novela, A la Costa, pues la trama o historia consiste en el movimiento espacial del protagonista, Salvador, desde Quito hacia la Costa. Este viaje por la geografía nacional funciona como una exploración de espacios que vienen asociados con elementos económicos, políticos y hasta psicológicos, y que van dibujando un genio ecuatoriano. De forma que la narración no solo se apropia textualmente de la geografía ecuatoriana, sino que le atribuye un contenido eminentemente cultural.

En realidad, esta relación original entre narrativa y geografía, una geografía en la que -insisto - los espacios topográficos también son espacios eminentemente humanos, contribuye a la representación de un territorio tal y como lo definen Lévy y Lussault. Si bien conciben Lévy y Lussault (2003, 910; la traducción es mía) el territorio como un simple "espacio con métrica topográfica", lo piensan ante todo como una "organización de recursos materiales y simbólicos capaces de estructurar las condiciones prácticas de la existencia de un individuo o de un grupo social, así como de informar, de forma reflexiva, a este individuo o colectivo sobre su propia identidad". Lo vemos, el concepto de territorio implica una geografía necesariamente cultural, por asociar el espacio topográfico con la noción de identidad, tanto individual como colectiva. En la novela $A$ la Costa, el trato literario de los espacios precisamente va moldeando territorios que dan a ver una forma de "comunidad imaginada" en palabras de Benedict Anderson (2009, 19), es decir, que le permiten a uno/una representarse mentalmente a los miembros de la comunidad nacional, aun cuando nunca llegará a conocerlos a todos.

Partiendo de la observación según la cual la narración produce un territorio cargado de "recursos simbólicos" (Lévy y Lussault 2003, 910), procuraremos entender los valores que asumen los espacios costeños, valores que no solo son económicos, políticos o ideológicos, sino también identitarios y hasta espirituales. Efectivamente, modelan un genio, 
un Volksgeist singular en el panorama cultural de la época, por tener una dimensión sublime, la misma que caracteriza, por cierto, la producción pictórica del Martínez paisajista.

\section{LOS VALORES ECONÓMICOS DE LA GEOGRAFÍA: LA COSTA COMO ELDORADO}

No es el caso volver aquí al contexto económico de finales del siglo XIX; solo recordemos que en 1899 el país exportaba la quinta parte de la producción mundial de cacao (Chiriboga y Piccino 1982, 15). La magnitud de la bonanza agroexportadora permitió una acumulación inédita de capital, valiéndole al cacao la apelación de “pepa de oro”. Las haciendas cacaoteras, situadas en su mayoría en el hinterland guayaquileño, poco poblado todavía, necesitaron entonces de una mano de obra creciente, atrayendo a migrantes serranos. Guayaquil se convirtió en un pujante puerto y en una ciudad dinámica, en la que se concentraron los beneficiarios económicos y sociales del auge cacaotero, entre ellos los "gran cacao" que contribuyeron a la victoria de la Revolución liberal, en 1895 (Sinardet 1998a; Sinardet 2007). Costa y Sierra representaron entonces los dos elementos de una nación "bicéfala” en palabras del geógrafo Deler (1981), por significar dos modelos de desarrollo y dos modelos de sociedad. Este "bicefalismo" precisamente lo describe A la Costa a través de la trayectoria espacial de Salvador, uno de estos migrantes serranos en busca de oportunidades en el Eldorado ecuatoriano. El quiteño se establece como mayordomo en la hacienda cacaotera El Bejucal y descubre, maravillado, la vitalidad y la riqueza de la agricultura costeña, descrita como espléndida y generosa: "La rica agricultura de la zona tórrida cantada por Bello, estaba allí. El sombrío cacaotal de troncos tortuosos y alineados simétricamente, mostraba a los ojos admirados de Salvador calles obscuras que terminaban en una lontananza azulina y vaporosa" (Martínez 1904, 95).

La naturaleza costeña la considera como la promesa de un futuro mejor el joven quiteño venido a menos, a pesar de su esmerada educación y de sus esfuerzos por conseguir un empleo decente: “Toda esa tierra de promisión, rodeada de un cinturón de bosques azulinos, casi diáfanos, silenciosos a esa hora, inacabables bosques que esperan la acometida del 
hacha para caer dejando su puesto al plátano o al cacao, el rey inamovible de la agricultura costeña" (96).

El agro costeño como espacio de valores económicos positivos lo pintan también las descripciones extremadamente precisas del arte de producir cacao, cuyo realismo raya con lo documental. Salvador reside 18 meses en El Bejucal, de forma que son todas las etapas del ciclo cacaotero las que analiza el narrador omnisciente, desde el desbrozar nuevos espacios (el "zocolar") con fuego (la "roza"), el sembrar, la cosecha, hasta el acondicionamiento de las pepas y las modalidades de su expedición y transporte a Guayaquil donde serán exportadas. Asimismo, la narración se detiene en la organización de El Bejucal, una hacienda tan inmensa que llega a las faldas andinas (107-108). Describe las condiciones de vida de la mano de obra, la jerarquía de los trabajadores y las tensas relaciones entre ellos, por lo que el agro costeño se presenta también como un sistema social que permite evocar las especificidades de la hacienda cacaotera ecuatoriana.

En El Bejucal viven representantes de casi todos los componentes de la población ecuatoriana, mulatos, negros, montuvios, serranos mestizos y blancos, cholos, unos indios también, bajo la tutela del dueño y patrón, don Antonio Velásquez. La influencia costumbrista es visible en la muestra de arquetipos humanos cuya psicología todavía está definida según características "raciales", conforme al positivismo y al darwinismo social aún influyentes a comienzos del siglo XX. Frente a serranos educados y amables, el administrador Fajardo está descrito como un "mulato de formas hercúleas, de maneras más que groseras, de gran ignorancia en todo lo que no fuera sembrar, cultivar y cosechar cacao" (108), mientras que los peones montuvios resultan "embrutecidos por el alcohol y las pasiones más innobles” (149). Además de enfrentar el clima insalubre y las rudezas de una naturaleza que le puede ser hostil al hombre, Salvador, el arquetipo del serrano distinguido y culto, debe aguantar la mezquindad y la envidia de los empleados costeños, desesperado por poder medrar algún día: "Salvador veía que la vida de mayordomo en esa hacienda, era una prisión sin esperanza de libertad, un embrutecimiento del espíritu, una lucha sin tregua contra el clima, los bichos venenosos y los hombres" (122).

$\mathrm{Al}$ respecto, el realismo notable de las descripciones de los trabajos del campo contrasta con la presentación atenuada y endulzada de la organización social de la hacienda. Por limitarse a mostrar la interacción entre tipos costumbristas superficiales, desprovistos de verdadera interioridad y 
personalidad, el narrador no relata los mecanismos que permiten el control de la mano de obra por el patrón, el endeudamiento sistemático mediante la tienda de raya, propiedad del terrateniente también, o las prácticas coercitivas disimuladas detrás de la relación contractual y asalariada. Tampoco evoca las estrategias poco legales de concentración latifundista. El realismo de Martínez se atiene al trato de la geografía, y solo será con la llamada “Generación del Treinta”, con el Grupo de Guayaquil en el caso costeño y la novela indigenista en el caso andino, cómo el realismo social se dedicará a analizar la hacienda como un sistema de dominación, denunciando su iniquidad y su crueldad. Para Salvador, las condiciones adversas de El Bejucal no residen en el sistema inherente a la hacienda, sino en un clima inclemente, en la personalidad despótica y grosera del administrador y en la obligación de alternar con peones toscos e ignorantes, cuyas conductas ofenden su decencia y rectitud moral. Por lo cual no resulta sorprendente que la figura más positiva sea la del terrateniente, generoso, justo, benevolente, sinceramente preocupado por el bienestar de sus empleados. Incluso actúa don Antonio como un deus ex maquina al reconocer los méritos personales de Salvador y al obrar por su felicidad, precisamente en el momento en que el joven, debilitado por el tifus, está a punto de abandonar y de renunciar a todo. Lo vemos, para Salvador, la Costa sí es el Eldorado, la promesa por fin cumplida de una vida mejor.

\section{UNA GEOGRAFÍA IDEOLÓGICA: LOS ESPACIOS AL SERVICIO DE LA DEMOSTRACIÓN POLÍTICA}

Desde esta perspectiva, A la Costa pertenece al género del Bildungsroman, en el que un joven todavía ingenuo, frágil, cuando no enfermizo como es el caso de Salvador, lleva a cabo un recorrido espacial que también es iniciático, enfrentando obstáculos y dificultades que progresivamente aprende a superar con valor y voluntad. El Bejucal representa el espacio del aprendizaje en el que Salvador acaba adquiriendo fuerza física, energía, virilidad y madurez. Recuperado ya del tifus, el joven conoce un ascenso fulgurante, cuando don Antonio, impresionado por su determinación e inteligencia, lo nombra responsable de la tienda de raya primero, administrador de la hacienda luego (un administrador respetado por los peones 
más feroces, los mismos que lo despreciaban y maltrataban a su llegada de Quito). Salvador no solo se salva de la pobreza y de la mediocridad, sino que se casa con la bella y dulce Consuelo; consuelo de todas las penas y humillaciones sufridas - la onomástica jugando un papel alegórico determinante en la novela-.

Aquel desenlace significa el triunfo de la educación y de la tenacidad sobre la ignorancia y la apatía, mostrando simultáneamente la superioridad del liberalismo en esos años de institucionalización de la Revolución liberal —la novela se publicó en 1904- Cabe recordar que Luis A. Martínez defendió el proyecto modernizador y laico liberal como diputado de Tungurahua de 1898 a 1899, ministro de Instrucción Pública en 1903 y senador. En A la Costa, elabora una demostración de corte político, mediante la construcción dual de la narración, a manera de un díptico en el que las dos partes de la novela se hacen eco con un juego de contrapuntos. Retrata a dos ecuadores en los que todo parece oponerse, en los que los espacios geográficos asumen valores ideológicos (Sinardet 1998b). La capital representa el espacio rancio de la degradación, corrupción y degeneración, vinculado con el conservadurismo y el clericalismo; este espacio del Tánatos remite a un universo moribundo que mira haci el pasado. En cambio, la Costa mira al futuro como espacio de una fuerza vital optimista y constructiva; de esa energía del Eros da fe la naturaleza espléndida y fértil. Representa el espacio de la marcha ineludible del progreso hacia una sociedad emprendedora y moderna. No es casualidad si el quiteño Salvador, de nombre programático, encuentra su salvación en la Costa. Va conquistando una dignidad y una emancipación que la Sierra le negó a pesar de sus numerosas cualidades. La Costa no es solo un espacio socio-económico, sino un espacio ideológico del que debe emerger una clase media ejemplar, motor del desarrollo nacional y de la edificación de una sociedad equitativa, basada en el reconocimiento del mérito personal, de la que Salvador, ya ascendido a administrador, es una figura emblemática. El joven hasta encuentra una forma de regeneración mental y moral en el contacto con el medio costeño, por más duro que este resulte:

Salvador, rejuvenecido moralmente, encontraba en él, energías nunca sospechadas y una voluntad férrea para el trabajo. Se veía fuerte, enérgico, y confiaba en sus fuerzas. ¡Atrás las ideas negras y pesimistas! Atrás ese odio a la humanidad entera, a esa humanidad que, si encierra tipos repugnantes, cuenta también en sus filas a una Consuelo y a un 
Velásquez. La fortuna esquiva por fin le mostraba el rostro sonriente y él bendecía la idea que le impulsó a huir de Quito e internarse en esa Costa tan alabada por unos y tan maldecida por otros. (Martínez 1904, 153)

Salvador es el único de su familia, conservadora y muy católica, por cierto, en lograr huir de una maldición quiteña que roe, corrompe y destruye económica, social, mental y moralmente. Débil, desprovisto de voluntad y de carisma, timorato e indeciso, cada vez más solitario y angustiado, el difunto padre de Salvador llevaba en sí el fatum de la degeneración. Al migrar a la Costa, Salvador se emancipa de esta figura paterna mórbida, símbolo de una sociedad condenada; renace a sí mismo, fuerte y dueño de su destino. Escapa también de la corrupción moral, otra faceta de la degeneración quiteña que acabó con su hermana Mariana, violada por un sacerdote y obligada a prostituirse. En la Costa, Salvador no solo funda una nueva familia, sino que encuentra en don Antonio Velázquez, el generoso oligarca, una figura paterna (Sinardet 2000), "un verdadero padre" (Martínez 1904, 154).

Sin embargo, Salvador fracasa precisamente cuando obtiene un lugar, una posición en el espacio costeño. Se ve simbólicamente paralizado por un mal misterioso ${ }^{1}$ que no es sino la metáfora del Tánatos y la realización de esta fatalidad mortífera que ya destruyó a los suyos. La narración se concluye con la muerte del protagonista después de una dolorosa agonía, cumpliéndose el destino trágico del quiteño, quien ni siquiera llegará a conocer a su hijo por nacer. ¿¿Acaso no es Salvador el "[representante de] una raza mal configurada para la vida, que pronto sería eliminada”? (30) La idea de un determinismo biológico no es sorprendente en el discurso de la época, marcado por el positivismo; pero aquí principalmente sirve la demostración ideológica según la cual el Ecuador moderno no puede nacer de los restos de una sociedad rancia. En realidad, el país solo llegará a formar parte del concierto de las grandes naciones gracias a hombres nuevos, personificados por el amigo de Salvador, el joven Luciano, cuyo nombre lo designa como una figura luminosa y hasta solar. Liberal convencido,

1. Varios elementos de la narración tienen un carácter autobiográfico. En 1902, Luis A. Martínez, entonces administrador de una hacienda en la provincia del Guayas, padeció una polineuritis que lo paralizó totalmente y de la que solo se recuperó después de cinco meses en una clínica de Guayaquil. Fue durante su convalecencia cuando le dictó a su esposa la novela $A$ la Costa. 
valiente y vigoroso, Luciano encarna el esfuerzo y la perseverancia; es "un joven provinciano, descendiente de esa hermosa clase media, que no pica muy alto en asuntos de nobleza y que, sin embargo, por el talento, las aptitudes y el patriotismo, es la primera de la República” (13). Lúcido, Salvador bien entiende que Luciano encarna la luz del porvenir, por lo que, en su lecho de muerte, le encomienda a su esposa: "Esta es mi mujer, Luciano... abrázala" (165). Con estas palabras que recuerdan los enunciados rituales del matrimonio, Salvador también le confía a Luciano a su hijo por nacer, con lo cual libera a este del destino trágico que le esperaba. Con Salvador muere el viejo Ecuador, pero, con sus palabras, el quiteño salva a su descendencia, ubicándola en una nueva filiación, la del hombre nuevo, y en un nuevo espacio, el del Ecuador liberal en construcción.

\section{ESPACIO, ROMANTICISMO Y GENIO ECUATORIANO}

A pesar de su recorrido iniciático, Salvador no logra gozar o solo brevemente del éxito y de la felicidad. Es que el espacio costeño es ambivalente: tanto feraz y promesa de riqueza como amenazador y peligro para el hombre. Esta ambivalencia procede de la fuerza en definitiva indomable de una naturaleza indiferente a los dramas humanos, por situarse justamente más allá de lo humano. Las largas descripciones insisten en la inmensidad, belleza y energía de la Costa, retratando un edén suntuoso: "El sombrío huerto de cacao, da lugar a las dehesas de janeiro, limitadas en el horizonte por bosques azulinos, cortados a trechos por tortuosos y dormidos esteros o por grupos de cañas que parecen plumajes verdes y pomposos, que emergieran de un Océano de hierbas" (99).

Martínez conoce muy bien el agro costeño por haber sido administrador del Ingenio Valdez en Milagro, en la provincia del Guayas, en 1902. Fue para él una revelación descubrir la opulenta naturaleza costeña, como lo muestran los cuadros grandiosos que de ella hace en su novela, no sin lirismo:

Los bosquecillos de frutales de color verde negro, el tejado azulino de las haciendas, el blanco mate de los esteros y charcas, el gris claro de las cabañas ocultas a medias entre las frondas, los bosques eternos y lejanos que cierran el cuadro como en un marco de tul verdoso, las 
canoas esbeltas y ligeras que surcan las aguas; alguna blanca vela que asoma en una curva distante, las bandadas de garzas que vuelan perezosas sobre las charcas, las parejas de informes alcatraces que vienen desde el Océano a explorar la tierra; las humaredas parduscas de los incendios de los chaparros; el cielo nacarado que domina toda esa inmensidad sin límites; el azul turquí de algunas colinas y cerrillos que arrugan la planicie inacabable, y, por último, el sol, ese sol propio de la tierra tropical, que baña todo con lluvia de luz mágica y acariciadora; he ahí el cuadro que se presenta desde la proa de un vapor que navega en el río Guayas; río admirable, sin rival tal vez en el mundo, por su belleza y fecundidad; río que es arteria por donde circula a torrentes la vida de un pueblo viril ¡Río Guayas! El de las orillas paradisíacas; el de las aguas fecundas, jel inspirador de Olmedo, el que enloquece a los amantes de lo bello, el que hace suspirar la nostalgia al que alguna vez navegó por sus ondas encantadas! (99-100)

El hombre que tiene la suerte de desenvolverse en este edén majestuoso recibe de él una serie de bienes que no solo son económicos, beneficios de actividades productivistas, sino y sobre todo espirituales, porque le invitan a uno a encontrar su verdadero lugar en el universo, aun cuando este universo escapa de su limitado entendimiento. Al casarse con Consuelo, Salvador también se une con la fuerza fecunda de la geografía costeña. La noche de bodas se presenta como la comunión feliz del joven con los elementos - luna, viento, tierra, agua, cacao- de una naturaleza cómplice, acogedora y benévola. El goce sexual de la pareja lo redobla la misma naturaleza, lasciva, con la que los amantes parecen confundirse:

Salvador abrazó a su mujer, cubrióla de besos y levantándola en alto con aire triunfante, llevóle a la cámara nupcial...

La luna salía en ese instante tras la cordillera brumosa, plateando las lustrosas hojas de los cacaotales, las aguas tranquilas del río murmurante, y la faja de blanca niebla que se levantaba perezosa en un rincón del paisaje inmenso... El silencio augusto de los bosques, apenas era turbado por el soplo intermitente de la brisa que viajera desde el lejano mar, moría fatigada en brazos de la selva; y la tierra fecunda, incansable de los trópicos, exhalaba aromas desconocidos, como si fueran los de la eterna maternidad de la naturaleza. (152)

La "maternidad eterna de la naturaleza" anuncia ya el embarazo de Consuelo, cuyo hijo será también el fruto telúrico del feraz universo costeño. 
La representación de espacios exuberantes que obedecen a fuerzas primitivas y rebasan lo humano es característica del romanticismo tardío ecuatoriano, influenciado en particular por Johann Gottfried Herder (Puig Peñalosa 2015). Según Herder, el genio de los pueblos, el Volksgeist, es el verdadero y único actor, en última instancia, de la Historia; debe ser aprehendido desde su dimensión biocultural, lo cual implica volver al medio geográfico en que el grupo se desenvuelve. Su naturaleza, su esencia como pueblo, con toda su riqueza, no es sino la expresión cultural de su naturaleza como geografía. Esta naturaleza a la vez geográfica y espiritual la va explorando Martínez en su pintura, además de su novela. En sus obras, concibe al Ecuador como un todo orgánico en que está inscrita la sociedad humana, un todo mucho más vasto que esta, porque lo componen elementos que no son humanos, que son más grandes y más nobles que los hombres.

Para Herder, importa estudiar los usos y las costumbres, las tradiciones y los hablares locales, los tipos y las "razas" vinculados con el medio; ahora bien, es precisamente aquí la misión y función del costumbrismo. Es más, los cuadros de costumbres contribuyen a transcender los espacios representados en territorios, o sea, según Lévy y Lussault, en espacios dotados de elementos significativos que van definiendo una identidad colectiva. La narración propone una representación del Volksgeist ecuatoriano, al distinguir y observar une serie de condiciones y determinismos — climáticos, topográficos, biológicos - propios de un genio singular.

Por lo tanto, entendemos la pasión del narrador omnisciente por la descripción de la naturaleza y los paisajes, así como el entusiasmo y la emoción que suscitan. La geografía asume rasgos psicológicos y sentimientos que también son experimentados por los protagonistas, en un juego constante de correspondencias y reflejos, cuando no de identificación, como lo ilustra la noche de bodas. El espacio costeño como elemento autóctono remite a mucho más que rasgos económicos o políticos: revela valores del espíritu, es decir, una personalidad ecuatoriana. En un artículo sobre paisajismo, Martínez declaró que una pintura lograda no muestra servilmente, como lo haría una fotografía, el espectáculo de la naturaleza, sino que capta y visibiliza lo impalpable de tal espectáculo, su alma y su genio (Martínez 1898). El mismo Martínez se definió como un fiel observador de la naturaleza: "No pertenezco a ninguna escuela, soy profundamente 
realista, y pinto la naturaleza como es y no como enseñan los convencionalismos" (389).

La precisión de las descripciones paisajistas, la preocupación por el detalle, la minuciosidad de la redacción textual, no son sino la manifestación literaria de las prácticas pictóricas del autor: apuntan a una matriz identitaria, entre realismo, costumbrismo y romanticismo herderiano.

\section{LA EXPERIENCIA DE LO SUBLIME}

Hemos subrayado la ambivalencia inherente a una naturaleza que queda indiferente ante las aspiraciones y las luchas humanas El espacio acogedor bien puede convertirse en un espacio mortífero, como lo muestran las fiebres que diezman a los peones de la hacienda. Asimismo, los elementos, cuando furiosos, desencadenan una violencia terrible que arruina los esfuerzos humanos:

Sí, allí estaba la vida, esa exuberante vida, prodigiosa, mágica, nacida al beso amoroso del sol fecundo que incuba millones incontables de vegetales gigantes y de seres que se mueven por todas partes. Sí, allí estaba la vida, la creación incansable que no deja una pulgada de tierra abandonada por el hombre sin cubrirla con una planta, ni una hoja sin un insecto. Pero allí estaba también la muerte, que no es más que una transformación de la vida. La creación y la destrucción, la vida y la muerte activas, incansables, eternas. $Y$ en ese teatro, el hombre combate contra lo infinitamente pequeño del paludismo, del tétanos y de la tisis; desafía el colmillo de la serpiente equis, desafía a la misma selva, pulpo de mil brazos invisibles que devora en un mes lo que le hizo perder el hacha y el fuego en un año. (Martínez 1898, 95-96)

La naturaleza costeña no pertenece al reino humano, no lo considera siquiera. Es de otra naturaleza — sin juego de palabras-, soberana, dotada de su lógica y de su propio orden. En realidad, no es sino el escenario de un teatro de la vida en que los hombres, diminutos y débiles, se debaten desesperadamente. Ilustra una visión de la existencia como una lucha en la que el triunfo resulta una excepción.

Efectivamente, en este vasto teatro, la trayectoria de Salvador simboliza la del hombre extraviado en un universo en el que no logra ubicarse. El misterioso mal que lo afecta lo precipita brutalmente de la fe- 
licidad a la nada de la muerte, de una forma totalmente incomprensible. Las ambiciones sensatas de Salvador están barridas, desechadas por fuerzas incontrolables. Con lo cual el hombre no puede pretender ser dueño de su destino, pues el destino humano no depende de uno, sino de principios y de leyes que le son exteriores, ininteligibles, impenetrables, y que se le imponen de una forma necesariamente caprichosa, arbitraria e inmotivada. Confrontado a la ilusión de controlar su destino, Salvador experimenta desesperación e impotencia; entiende que es extraño a un universo cuyo significado queda elusivo. Siente la hostilidad primitiva de una naturaleza percibida como irracional y que, no obstante, le otorga bienestar. La felicidad, cuando posible, resulta precaria, por lo que la búsqueda desesperada de Salvador, que tanto sacrificio requiere, es utópica. Frente a un orden cósmico misterioso, la muerte representa la única certidumbre. Por vincular el espacio costeño con fuerzas superiores inalterables, la narración pinta un universo en el que las aspiraciones y esperanzas humanas quedan irrisorias, en el que el hombre mismo resulta insignificante. Le invita al lector a reflexionar sobre el carácter filosófico de la vulnerabilidad y de la vanidad.

Sin embargo, y por eso mismo, la confrontación con el espacio costeño también permite experimentar y sentir lo inconmensurable, lo infinito. Los paisajes, si bien son preciosos, nunca resultan solamente bellos; su violencia también espanta. La naturaleza sorprende, seduce, asusta, despista, provocando sentimientos de toda índole que apuntan a lo irreductible, a la imposibilidad de conocerla definitiva y totalmente. Raya con lo sublime tal y como lo define Schiller $(2005,37$; la traducción es mía):

Designamos como sublime un objeto frente a la representación del cual nuestra naturaleza física siente sus propias limitaciones, mientras que nuestra naturaleza razonable siente su superioridad, su independencia de toda forma de límite; un objeto, por tanto, con respecto al que somos físicamente más débiles, mientras que moralmente nos elevamos en ideas por encima de él.

Entendemos mejor el lirismo paisajista del narrador: este acompaña un proceso de elevación moral y espiritual. El trato de la geografía costeña desemboca en lo sublime, al invitarnos a aprehender una suerte de absoluto de la creación, a captar algo sagrado que suele escapársele al hombre — no hablaremos de Dios, pues el propósito no es religioso-. Se puede suponer que esta experiencia de lo sublime también es autobiográfica, 
pues Luis A. Martínez fue un andinista apasionado que, admitiendo que le faltaban las palabras, procuró expresar en sus cuadros las emociones suscitadas por el espectáculo de una naturaleza grandiosa, estupor, admiración, entusiasmo (Martínez 1994). De la fuerza transcendente de lo sublime toma conciencia Salvador, mientras exhala su último suspiro, como lo sugiere la frase que cierra la narración: "la cara tomó una expresión beática y bellísima, y los ojos vidriosos quedaron fijos en el Chimborazo, que allá, en el confín del paisaje inmenso, resplandecía con los últimos rayos del sol" $(1994,165)$. El volcán aéreo y resplandeciente une la tierra con el cielo, la Costa con los Andes, formando un conjunto descomunal y prodigioso que rebasa a la persona de Salvador y su destino. Al mismo tiempo, le revela a Salvador su esencia espiritual, como lo indica "la expresión beática" (165) de su cara, pues le permite vislumbrar lo que el hombre es incapaz de representarse y de imaginar siquiera: le permite acceder a un infinito que no puede concebir ni entender de forma inteligible.

Los espacios geográficos asumen aquí valores que también son filosóficos. De cierta forma, la naturaleza costeña recuerda lo que Kant llama un noúmeno, es decir, un objeto no fenoménico que surge como una cosa por sí escurridiza y elusiva (a la inversa del fenómeno que sí puede ser aprehendido y conocido). En definitiva, el arte es la mejor vía para captar aquel fenómeno. En A la Costa, el artista Martínez precisamente deja el pincel por la pluma para exponer con palabras su visión de lo sublime.

\section{CONCLUSIÓN}

La narración produce, apropiándose de ellos, un territorio de "recursos simbólicos” (Lévy y Lussault 2003, 910) de múltiples significados socioeconómicos, políticos, ideológicos, espirituales y hasta filosóficos. Conforman rasgos culturales que alimentan la definición posible de un genio ecuatoriano, de un Volksgeist que también es una "representación de sí” en palabras de los sociólogos Balibar y Wallerstein (1988, 128) cuando definen identidades nacionales. La geografía como soporte identitario permite la creación de un imaginario colectivo que es la condición de esa "comunidad imaginada" (Anderson 2009, 19) que debe cimentar a los ecuatorianos en un momento histórico de consolidación del modelo del Estado-nación. Para ello, con una admirable plasticidad, la narración 
se vale de diferentes corrientes e influencias literarias y estéticas, realismo, costumbrismo, lirismo, romanticismo, por lo que resulta difícil clasificar a ciencia cierta la novela $A$ la Costa. Es que se distingue por proponer una interpretación espiritual y filosófica de la geografía, muy original en la producción cultural de la época, mostrando la fragilidad y la vanidad de las aspiraciones humanas. No resulta desencantado ni pesimista el propósito; al contrario, apuesta por una elevación del alma mediante una experiencia de lo sublime que es también una experiencia de lo absoluto. Esta apuesta es la de un pintor, el paisajista autodidacta de inspiración romántica que fue Luis A. Martínez, antes de ser novelista. Aunque se lo conozca hoy como escritor, no fue un novelista que pintó, sino un pintor que escribió (expresión adaptada de Febres Cordero 2004).

\section{Lista de referencias}

Anderson, Benedict. 2002. L'imaginaire national. Réflexions sur l'origine et l'essor du nationalisme. París: La Découverte.

Balibar, Etienne, e Immanuel Wallerstein. 1988. Race, classe, nation, les identités ambigiues. París: La Découverte.

Chiriboga, Manuel, y Renato Piccino. 1985. La producción campesina cacaotera: problemas y perspectivas. Quito: CAAP / CECC.

Deler, Jean-Pierre. 1981. Genèse de l'espace équatorien. París: Institut Français d'Etudes Andines, Editions ADPF.

Febres Cordero, Francisco. 2004. "Tres pintores que escribían”. El Universo. 5 de septiembre.

Lévy, Jacques, y Michel Lussault. 2003. Dictionnaire de la géographie et de l'espace des sociétés. París: Belin.

Martínez, Luis A. 1898. "La pintura de paisaje en el Ecuador". Revista de Quito 1 (12): 385-94.

—. 1904. A la Costa. Versión electrónica, la Biblioteca Virtual Universal. https:// archive.org/details/ALaCostaLuisA.Martinez.

—. 1994. Andinismo, Arte y Literatura. Quito: Abya-Yala / Agrupación Excursionista Nuevos Horizontes.

Puig Peñalosa, Xavier. 2015. "Una introducción a la recepción y adaptación de la estética romántica en el Ecuador decimonónico: la influencia de Herder y la estética romántica de lo sublime en la literatura y la pintura de paisaje". Estudios de filosofia (52): 161-80. http://aprendeenlinea.udea.edu.co/revistas/ index.php/estudios_de_filosofia/article/view/25058/20701. 
KİPUS 49, enero-junio 2021

Sinardet, Emmanuelle. 1998a. "El mito de París y la oligarquía cacaotera en Ecuador (1895-1925)". Revista del Instituto de Historia Maritima XIII (23): 147 58.

—. 1998b. "A la Costa de Luis A. Martínez: ¿La defensa de un proyecto liberal para Ecuador?”. Bulletin de l'IFEA 27 (2): 285-307.

- 2000. "Les figures paternelles dans A la Costa de Luis A. Martínez (1904): l'impossible construction de soi". En L'image parentale dans la littérature de langue espagnole, editado por Amadeo López, 185-198. Nanterre: Université de Paris X-Nanterre.

—. 2007. "La oligarquía liberal ecuatoriana y su representación: la Exposición Universal de 1900". En Image et transmission des savoirs dans le monde ibérique et ibéro-américain, editado por Jean-Louis Guereña, 521-33. Tours: Presses Universitaires François Rabelais.

Von Schiller, Friedrich. 2005. Du Sublime. Traduit de l'allemand par Adolphe Régnier. Arlés: Sulliver. 